Proc. Indian Acad. Sci., Vol. C 2, Part 4, December 1979, pp. 435-449. (C) Printed in India.

\title{
A study on bullock carts. Part 1. Engineering analysis of the two-wheel bullock cart design
}

\author{
M R RAGHAVAN and H R NAGENDRA \\ Department of Mechanical Engineering, Indian Institute of Science, Bangalore 560012
}

MS received 20 October 1979

\begin{abstract}
An engineering analysis of the design of two-wheel bullock carts has been carried out with the aid of a mathematical model. Non-dimensional expressions for the pull and the neck load have been developed. In the first instance, the cart is assumed to be cruising at constant velocity on a terrain with the effective coefficient of rolling friction varying over a wide range (0.001 to 0.5$)$ and the gradient varying between +0.2 to -0.2 . Subsequently, the effect of inertia force due to an acceleration parallel to the ground is studied. In the light of this analysis, two modifications to the design of the cart have been proposed and the relative merits of the current designs and the proposed designs are discussed.
\end{abstract}

Keywords. Bullock carts; design; force analysis; performance; terrain; frictional resistance.

\section{Introduction}

There are over thirteen million animal-drawn carts in India, most of which are twowheel carts drawn by one or two bullocks or buffaloes. The design of the conventional cart with two large steel-rimmed wooden wheels has been evolved empirically by the village artisans over the centuries. These carts ply on unprepared terrains in predominantly rural areas and prepared terrains (metalled/tarred/concrete roads) in and around urban areas. To overcome the damage caused by these carts to prepared terrains, some of the two-wheeled carts have been fitted with steel axles and pneumatic wheels. The diameter of the pneumatic wheels is obviously smaller than the diameter of steel-rimmed wooden wheels of conventional carts. No data is available on the effect of a smaller wheel on the performance of the cart.

Recently, the basic mechanics of a two-wheel cart drawn by one or more animals has been analysed (Yajnik 1976). This analysis has been confined to a cart cruising on a level horizontal road. It has been observed that the optimum resultant pull* $P_{R} / W_{L}$ (where $\left.P_{R}=\left(P^{2}+W_{R}^{2}\right)^{1 / 2}\right)$ is virtually insensitive to variations of $\mu$ over the range of 0.1 to 0.5 and of $h / c$ over the range of 0.03 to 0.6 . What is required, however, is a more comprehensive analysis which also includes the study of the effects of gradient of the terrain, variations in the horizontal and vertical disposition of the centroid of the loaded cart, size of the wheels, etc., on the design and performance of the cart. A comprehensive engineering analysis of the two-wheel bullock cart design aimed at highlighting the weak features in the conventional

*A list of symbols appears at the end of the paper. 